\title{
The first solid-phase synthesis of bis(oxazolinyl)pyridine ligands
}

Avi Weissberg, Baruch Halak and Moshe Portnoy*

Supporting Information 


\section{Table of Contents}

General methods

3

${ }^{1} \mathrm{H}$ NMR of cleavage solutions 4-16

Gel-phase ${ }^{13} \mathrm{C}$ NMR of resins

$17-21$ 


\section{General Experimental Methods}

All experiments were performed under nitrogen atmosphere in oven-dried glassware with magnetic stirring.. The synthesis was performed on Imidate Wang Resin (0.72- 0.85 mmol/gr 1\% DVB, 100-200 mesh) purchased from Novabiochem. THF was dried over, and distilled from, sodium/benzophenone ketyl. $\mathrm{CH}_{2} \mathrm{Cl}_{2}$ was dried over, and distilled from, $\mathrm{CaH}_{2}$.

Solution ${ }^{1} \mathrm{H}(200 \mathrm{MHz})$, and ${ }^{13} \mathrm{C}$ NMR $(50 \mathrm{MHz}$ and $100 \mathrm{MHz})$ spectra were recorded in $\mathrm{CDCl}_{3} /$ TFA 1:1 with residual solvent peaks $\left({ }^{1} \mathrm{H}: 7.26 \mathrm{ppm},{ }^{13} \mathrm{C}: 77.16 \mathrm{ppm}\right)$ as reference. Gel-phase ${ }^{13} \mathrm{C}$ NMR spectra were recorded in benzene- $\mathrm{d}_{6}$. 


\section{${ }^{1}$ H NMR of Cleavage Solutions}

* - Residual solvents signals

** - Benzene (internal reference) signal

${ }^{1} H$ NMR of Cleavage Solution of $1 \boldsymbol{e}$

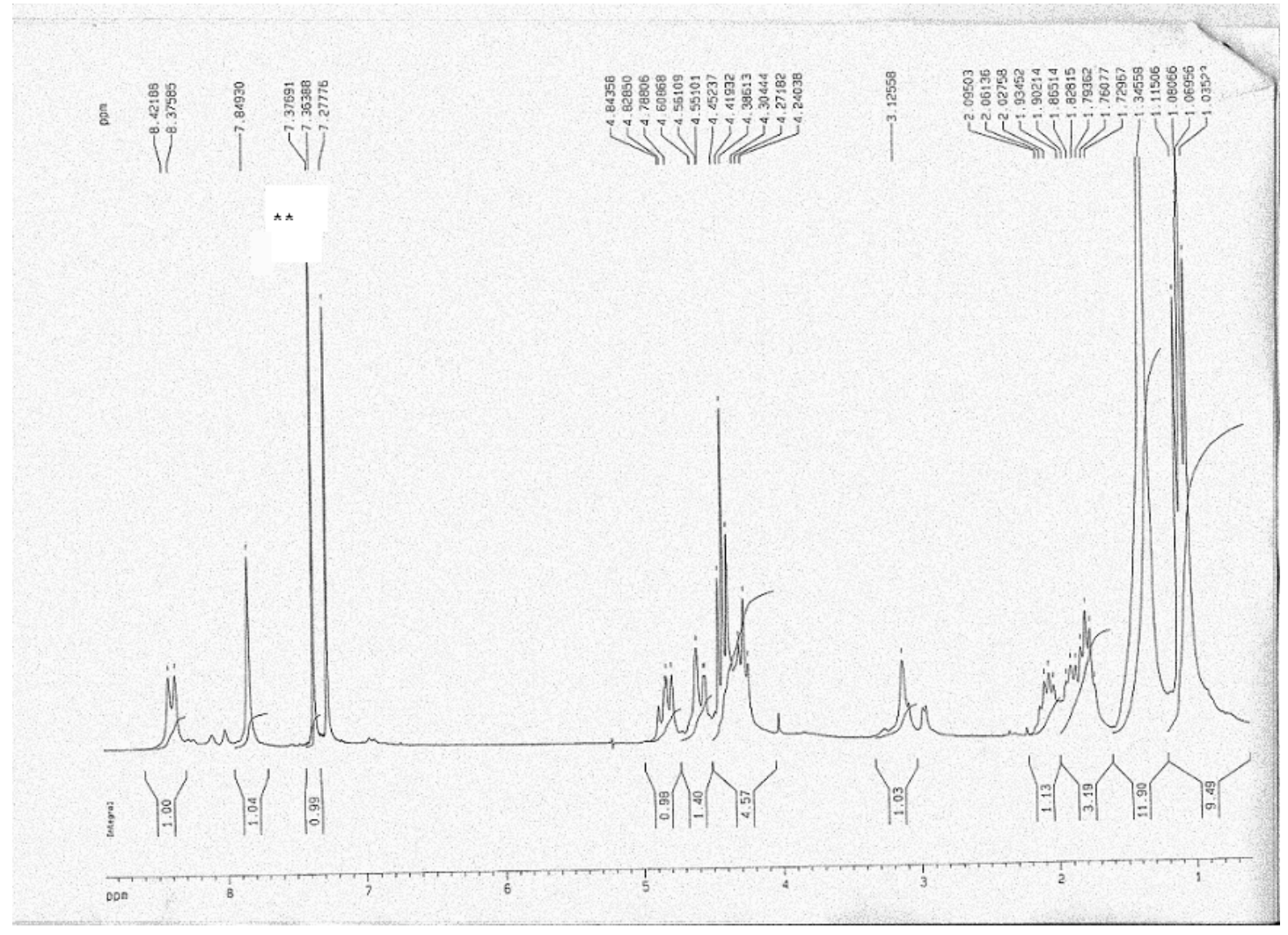




\section{${ }^{1} H$ NMR of Cleavage Solutions of 2}

2b

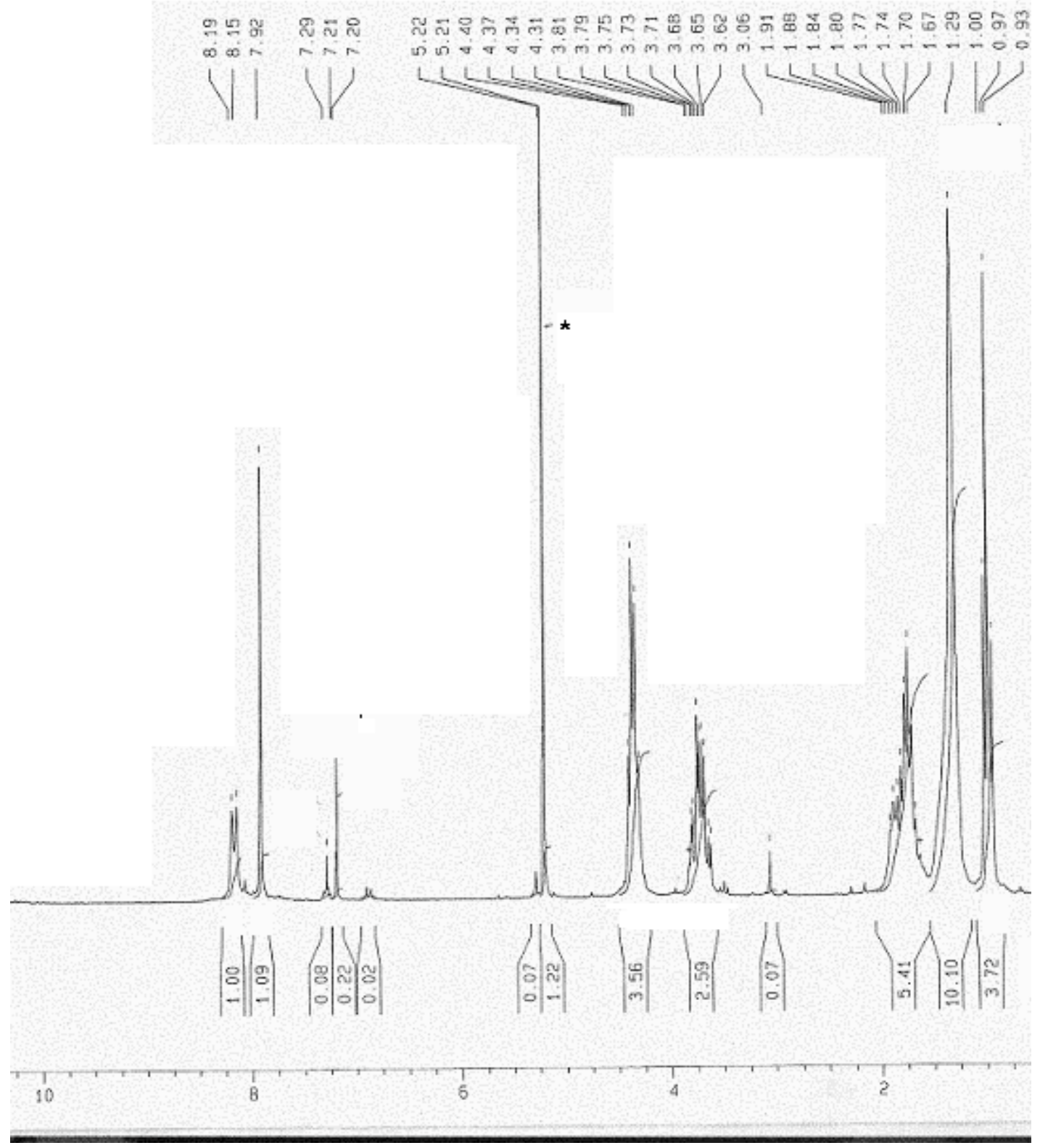


2c

ร

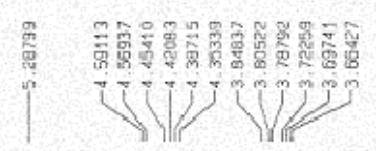

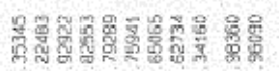

INTIJ O

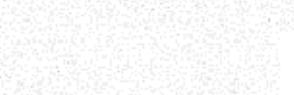

$\left.\right|_{i} ^{i *}$

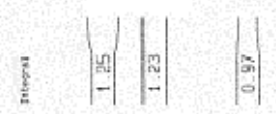

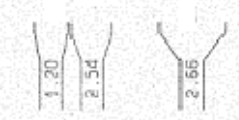

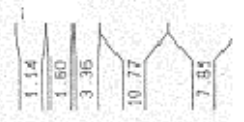

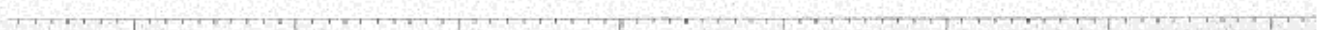




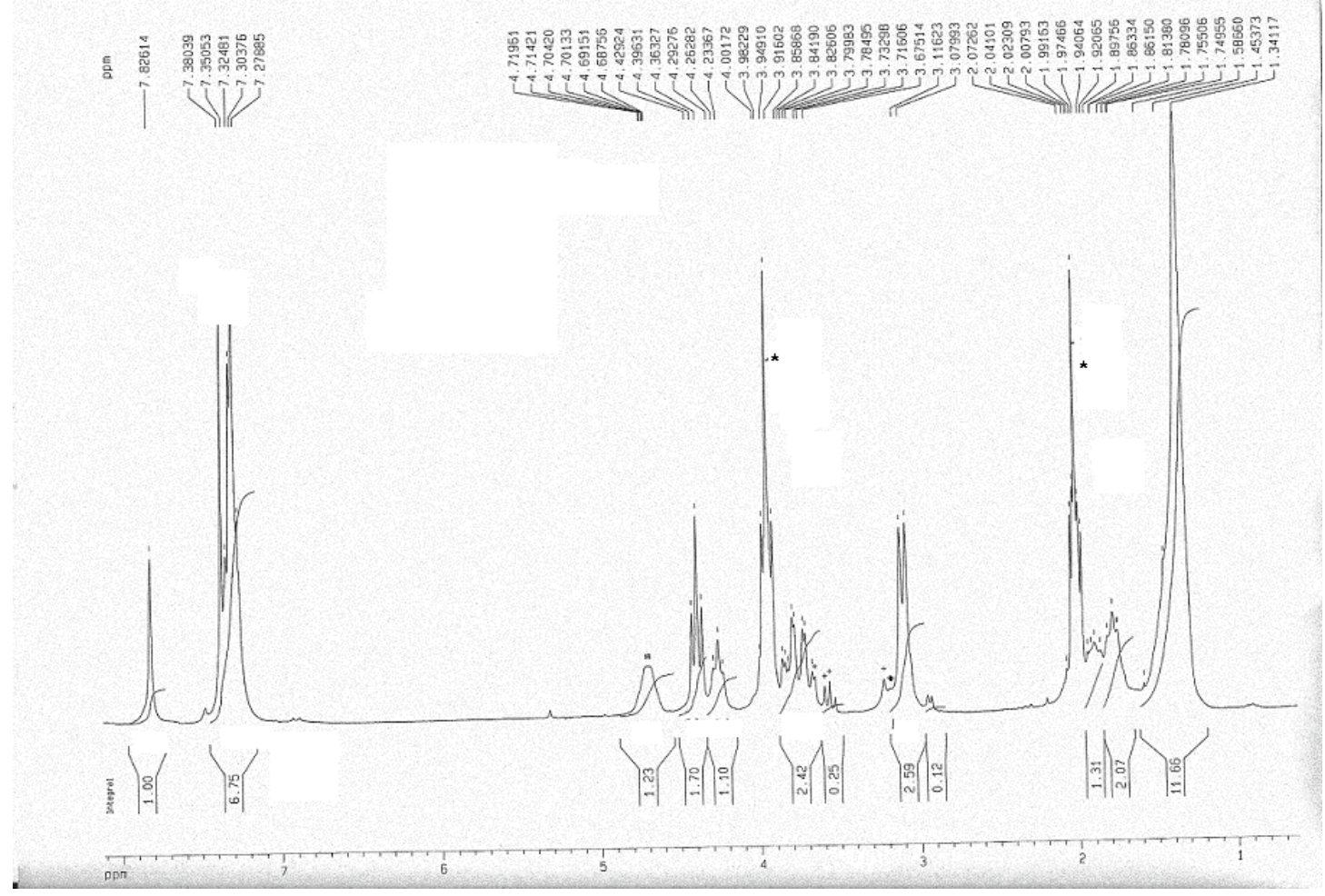


$2 \mathrm{e}$

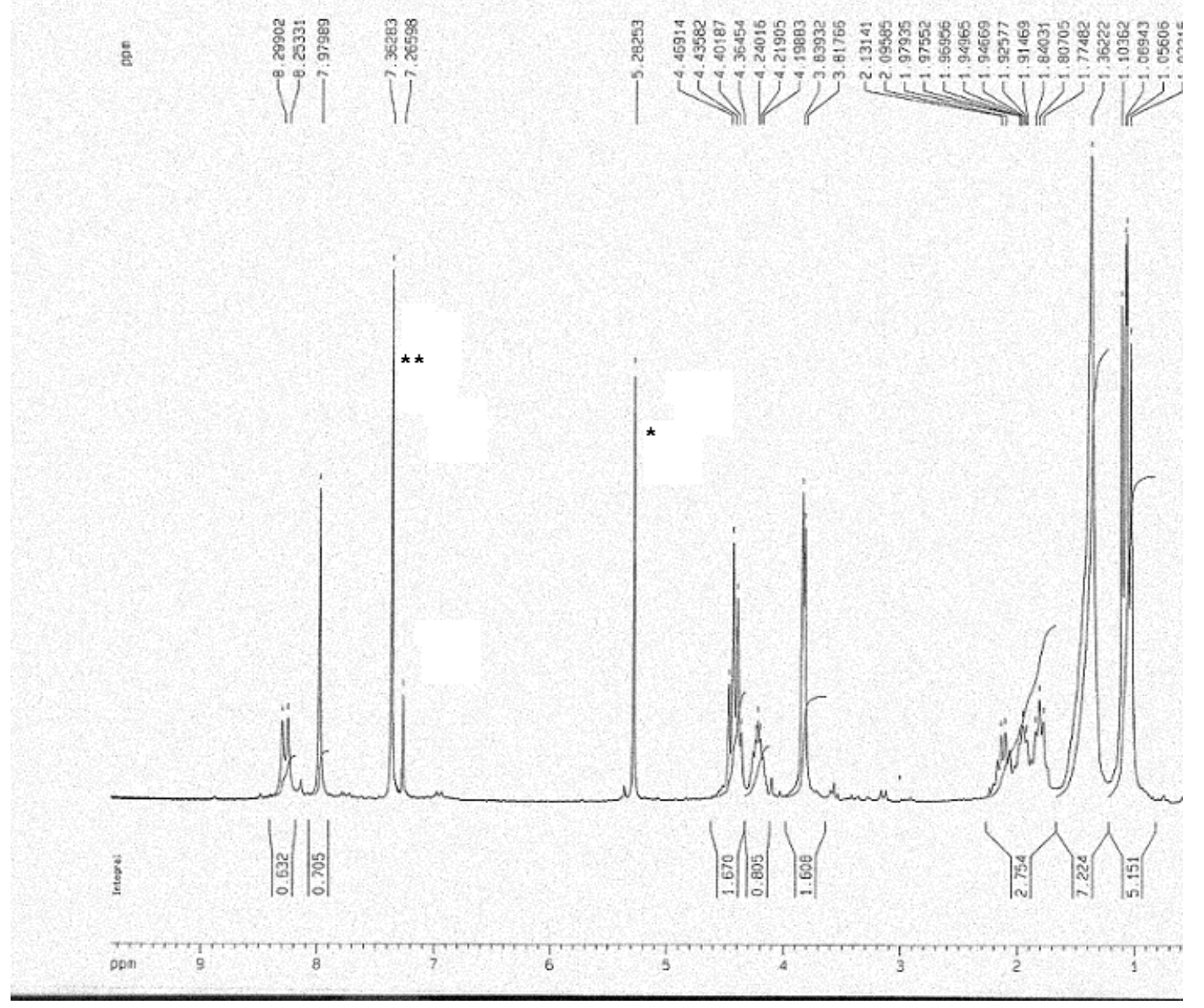




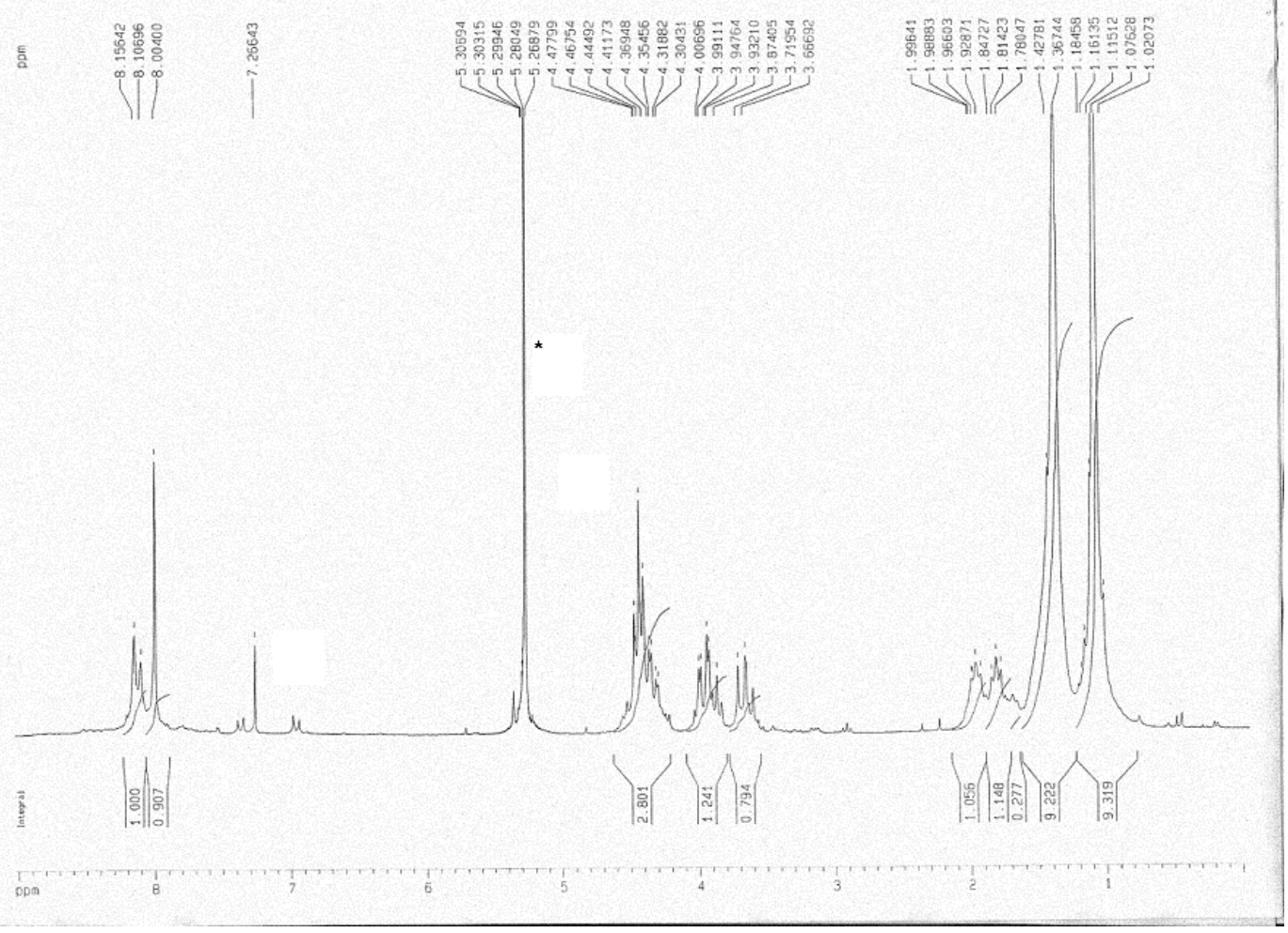


$2 g$

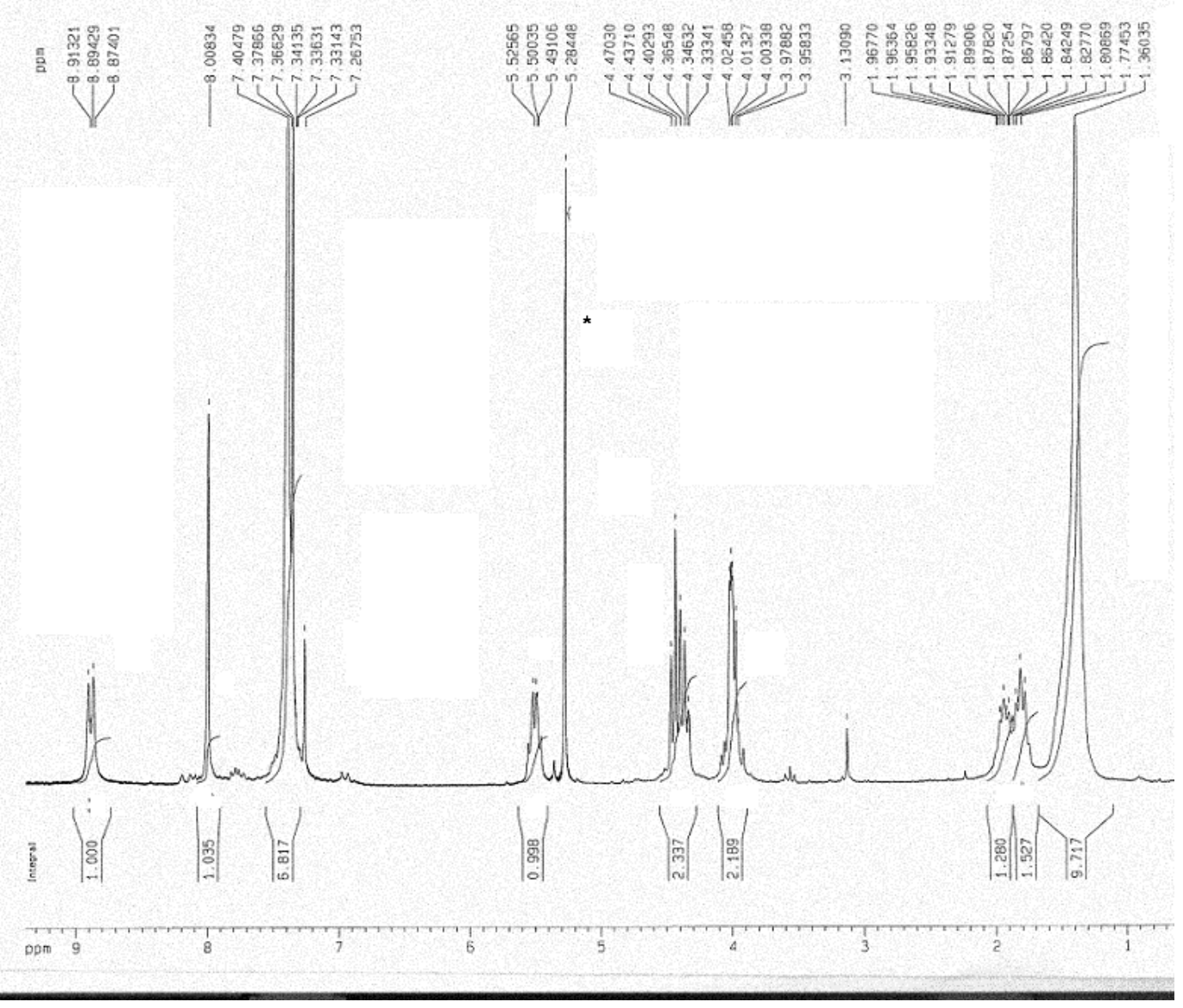




\section{${ }^{1} H$ NMR of Cleavage Solutions of 3}

3a

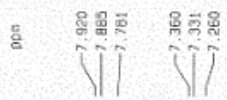

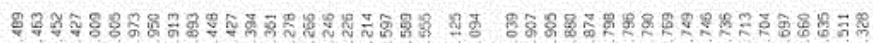

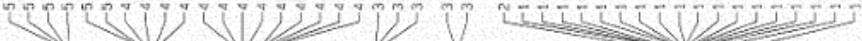

(4)

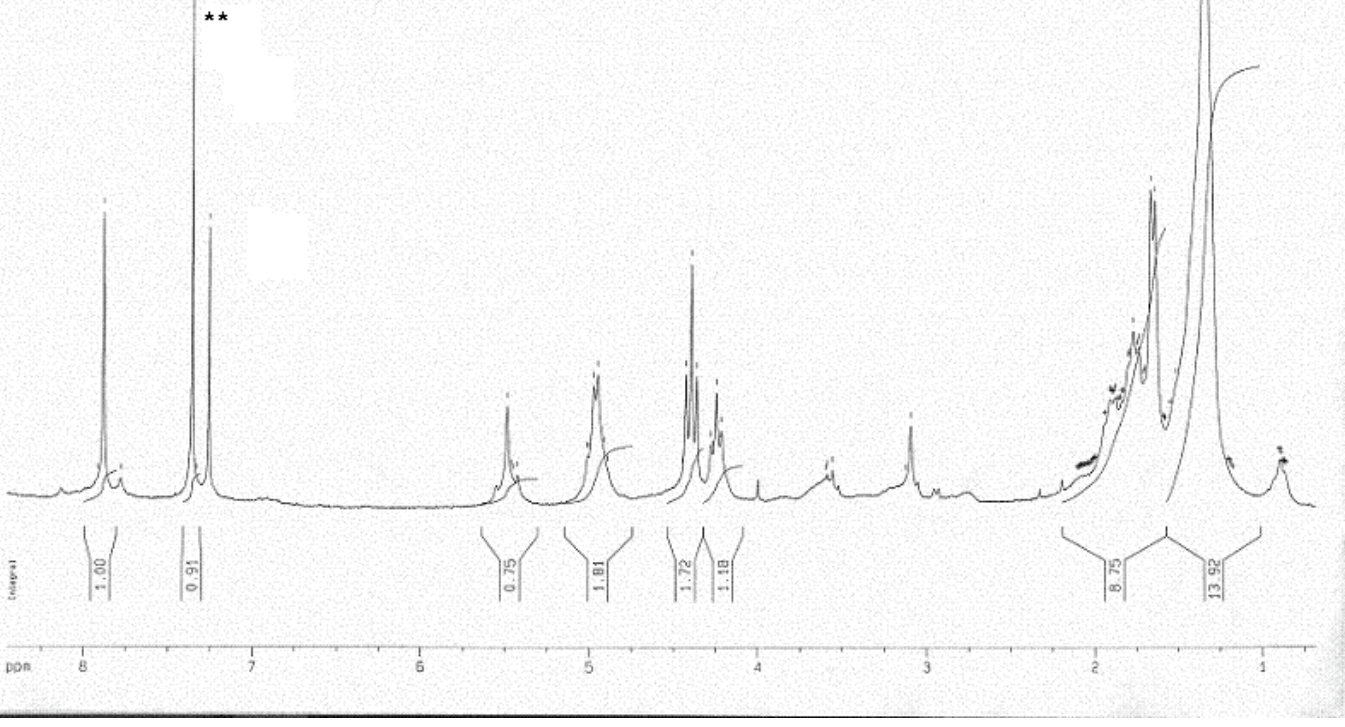


3b

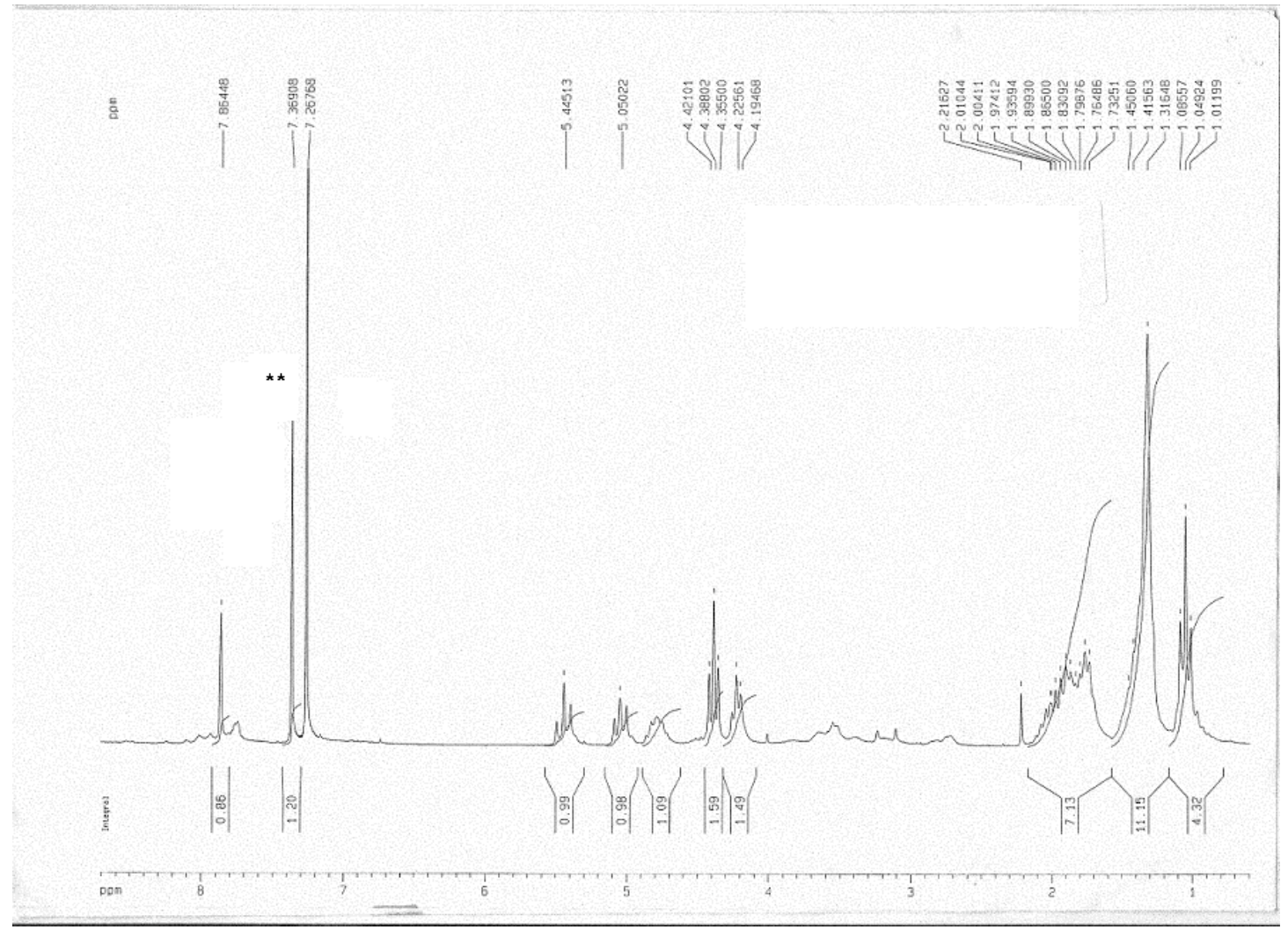


$3 c$

흠

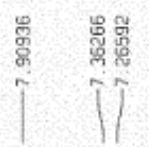

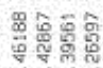

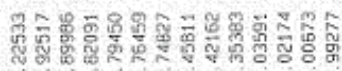

iji
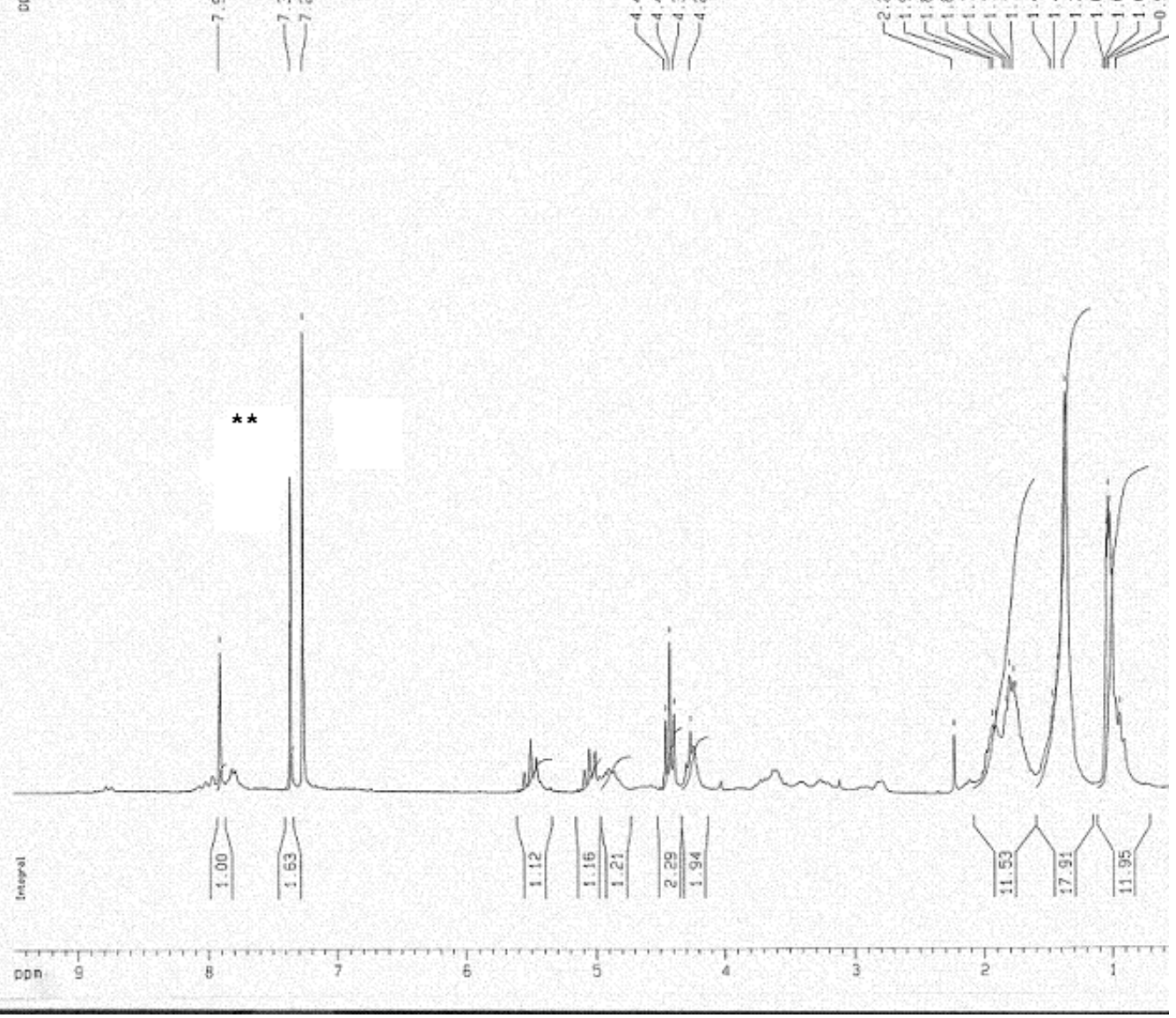
3d

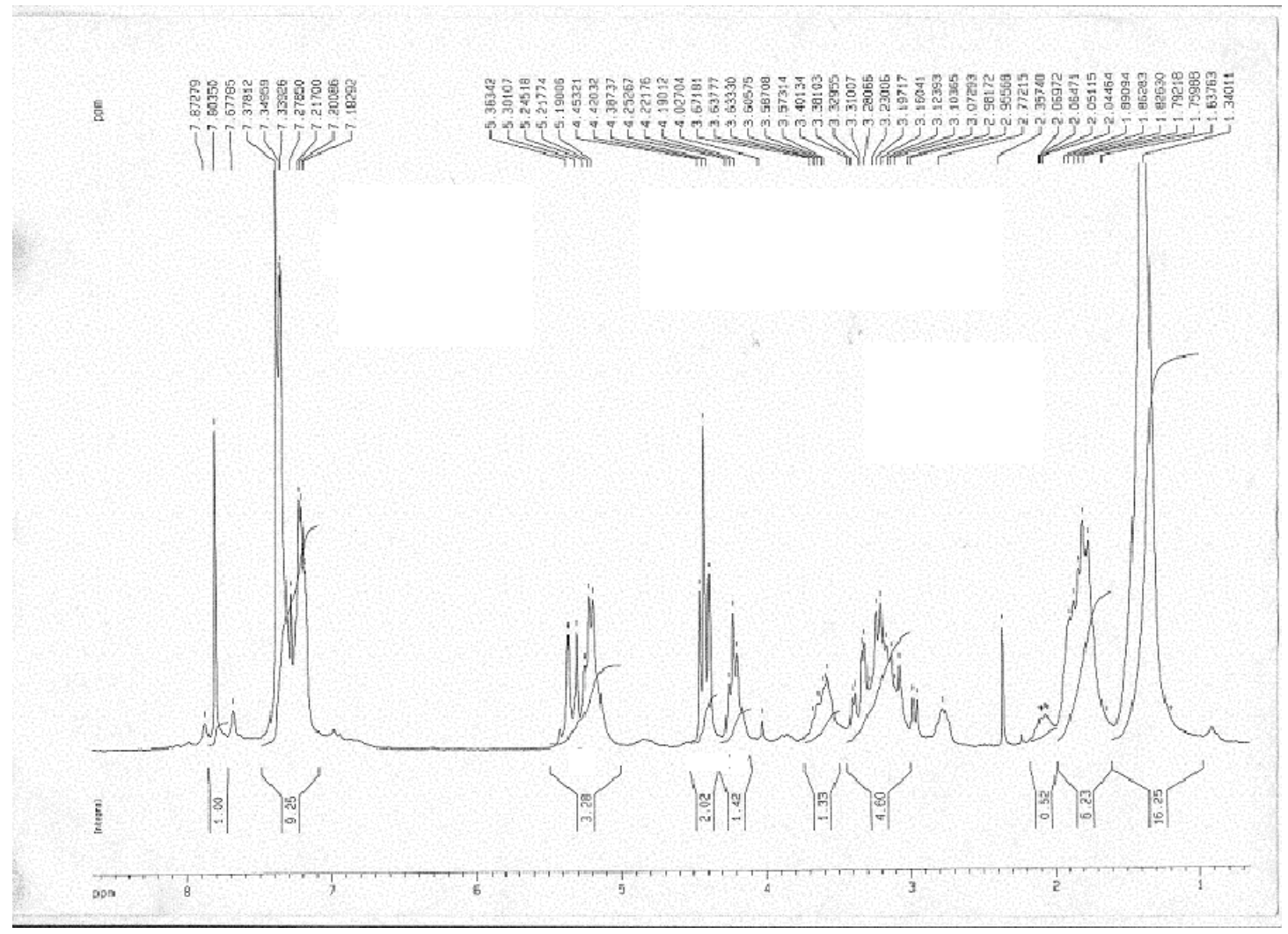


$3 e$

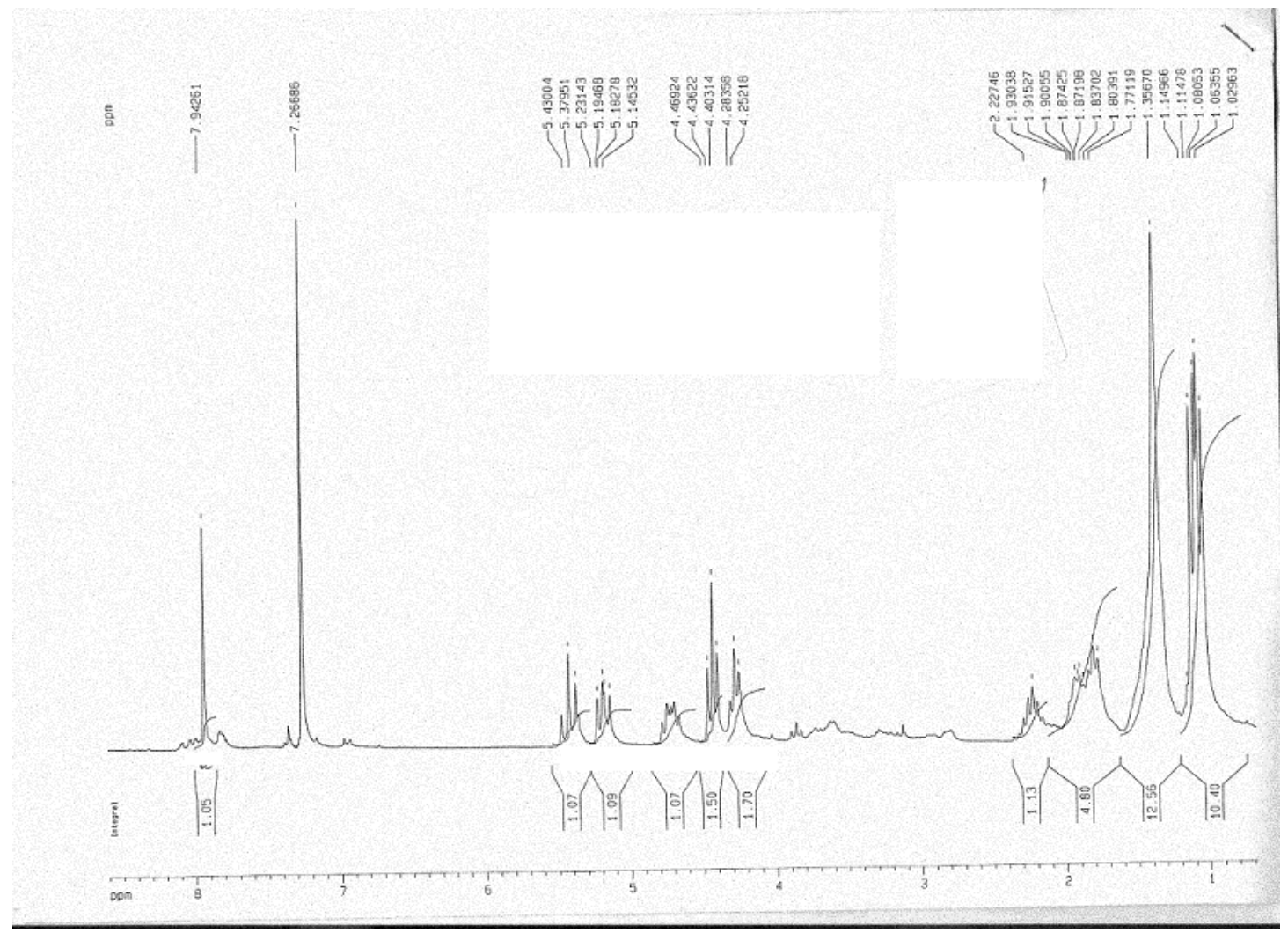


$3 f$

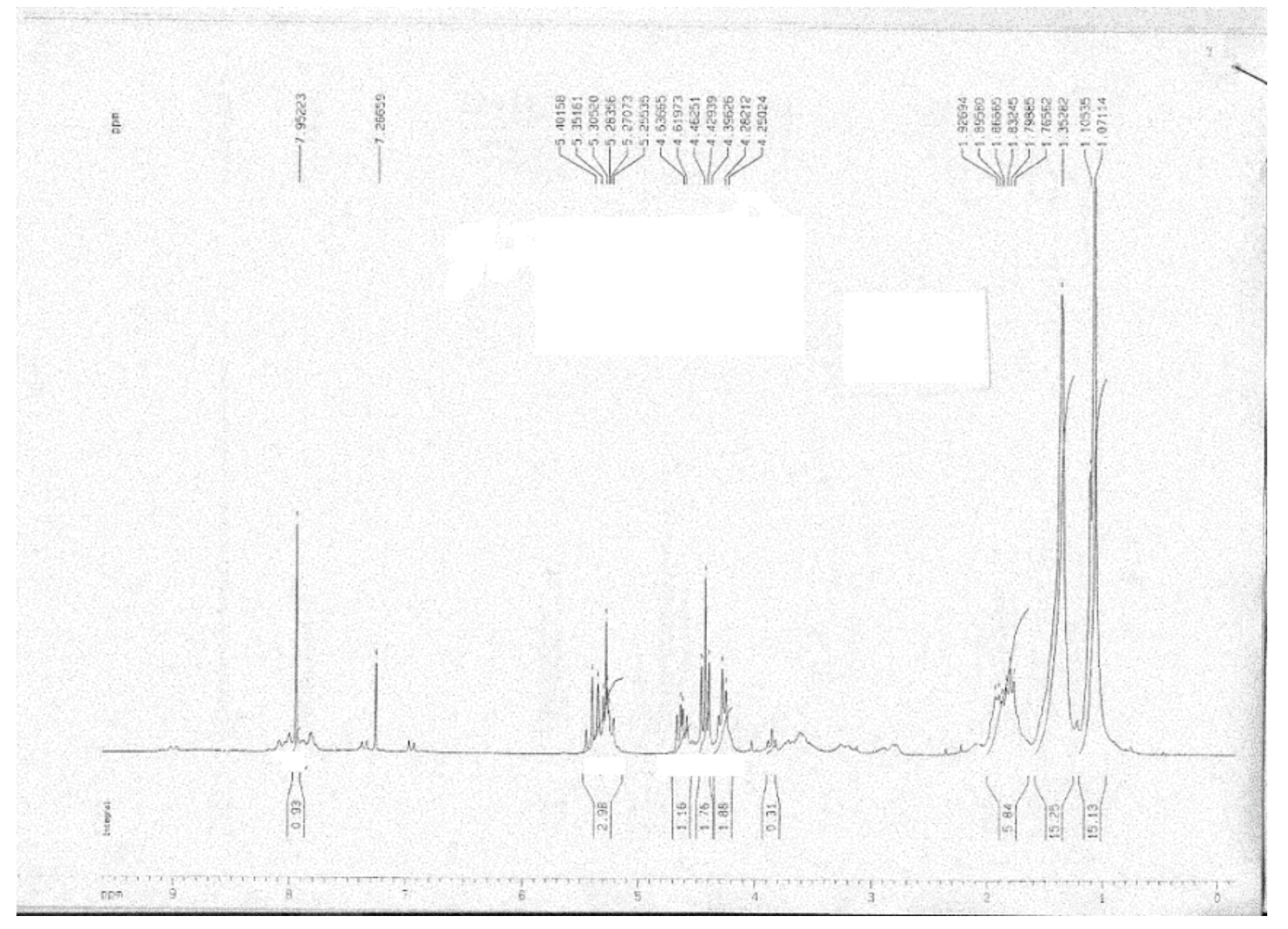

S 15 
Gel-phase ${ }^{13} \mathrm{C}$ NMR of 3

3b

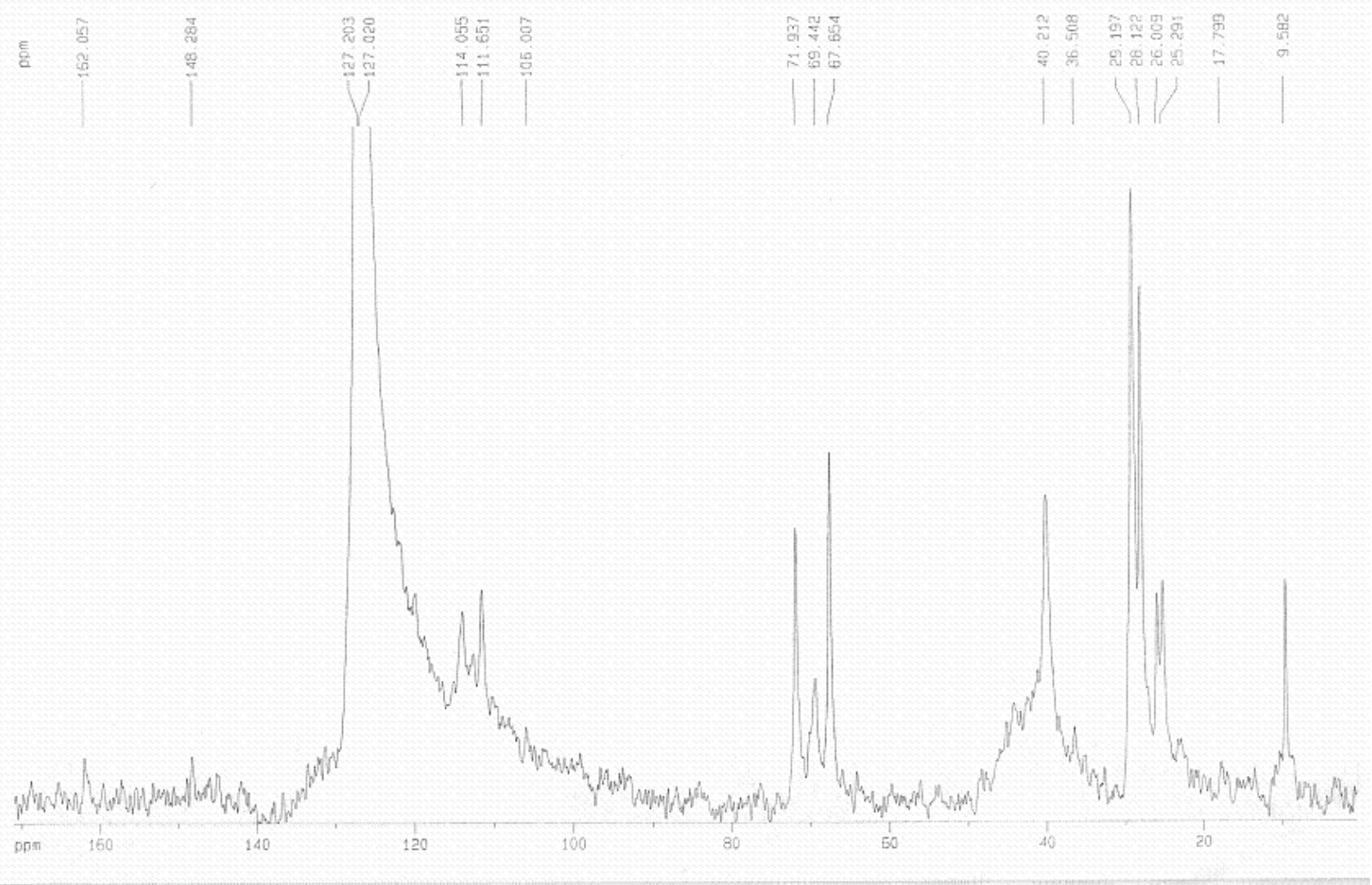


$3 c$

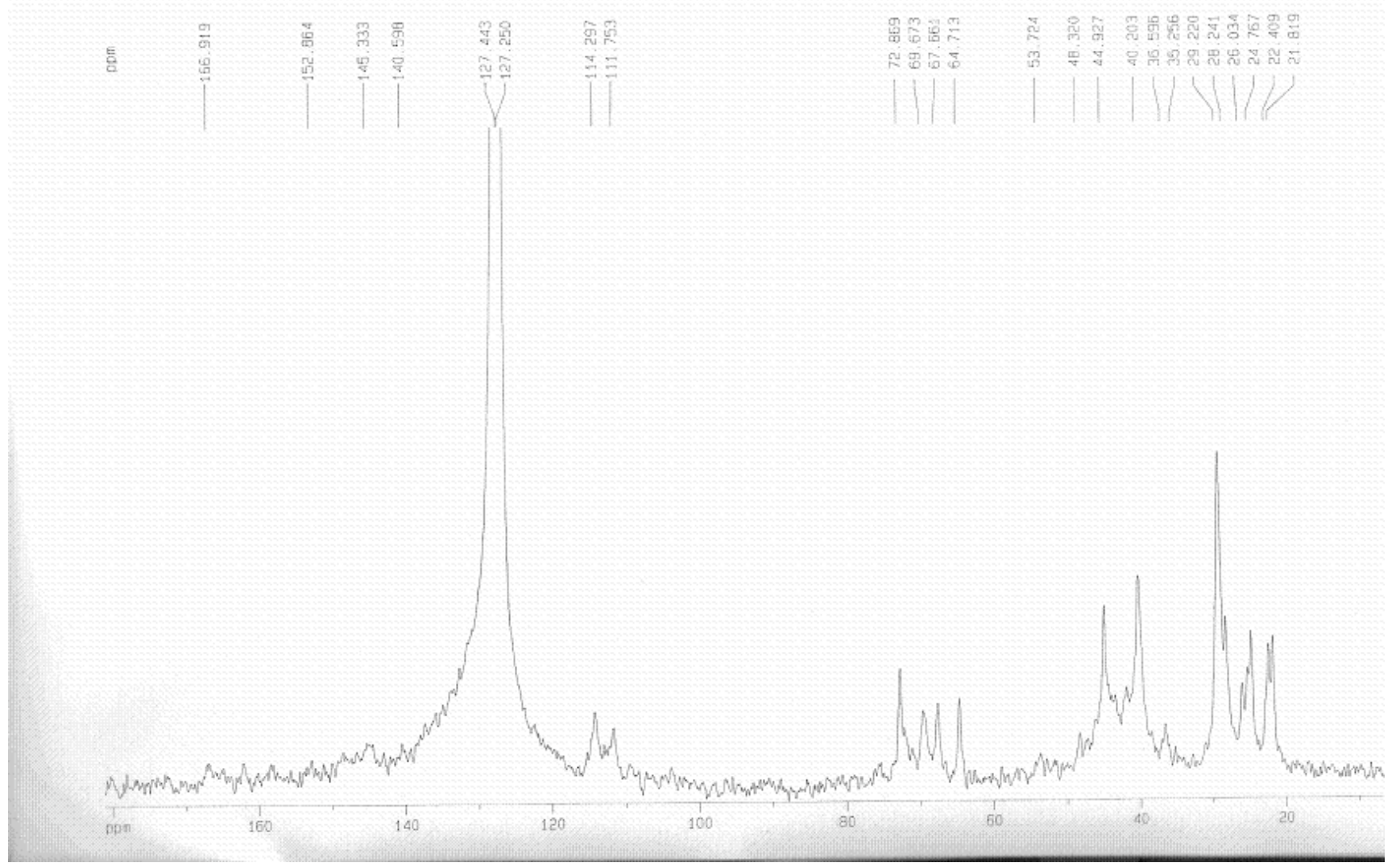


3d

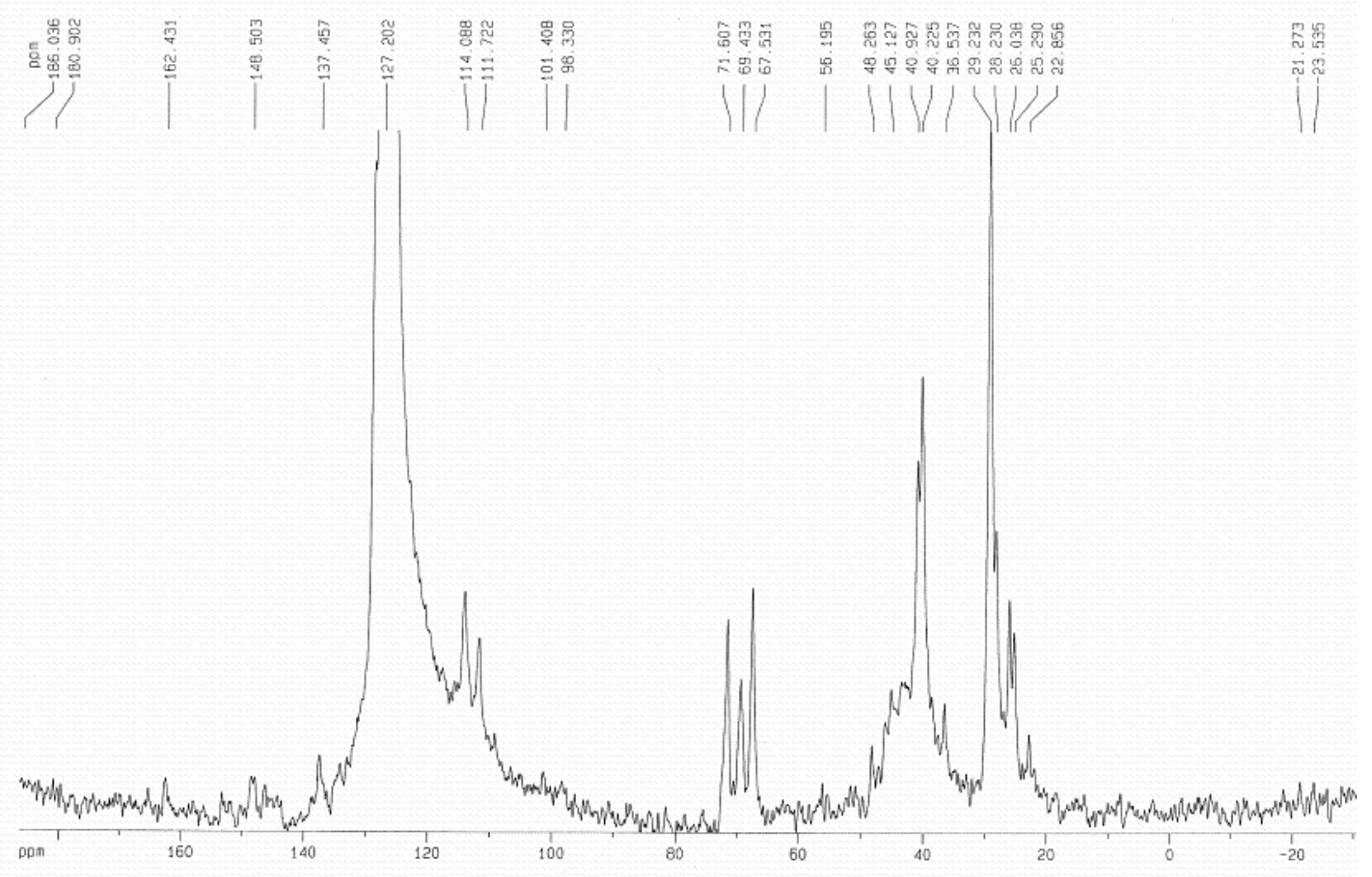


$3 e$

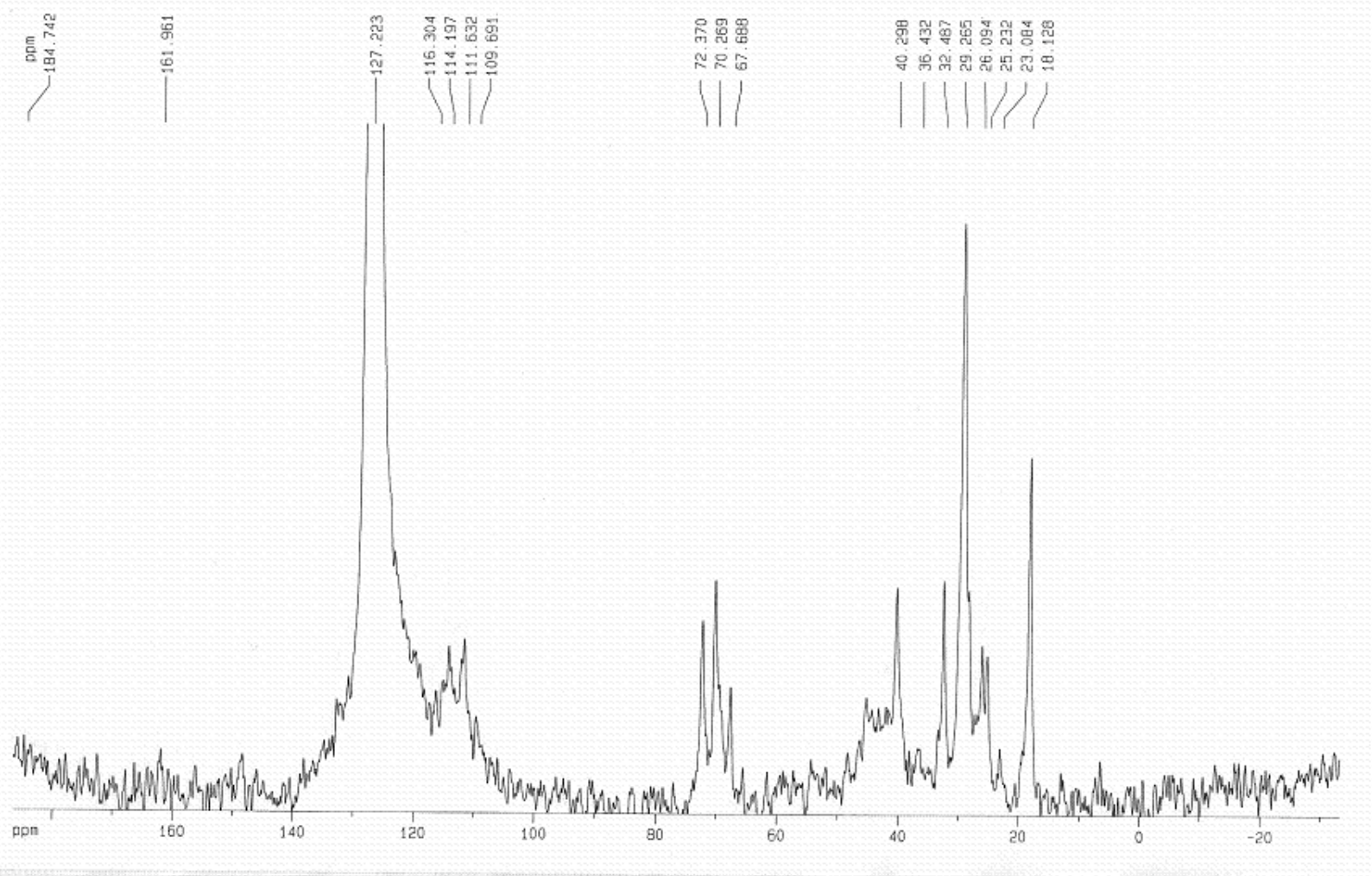




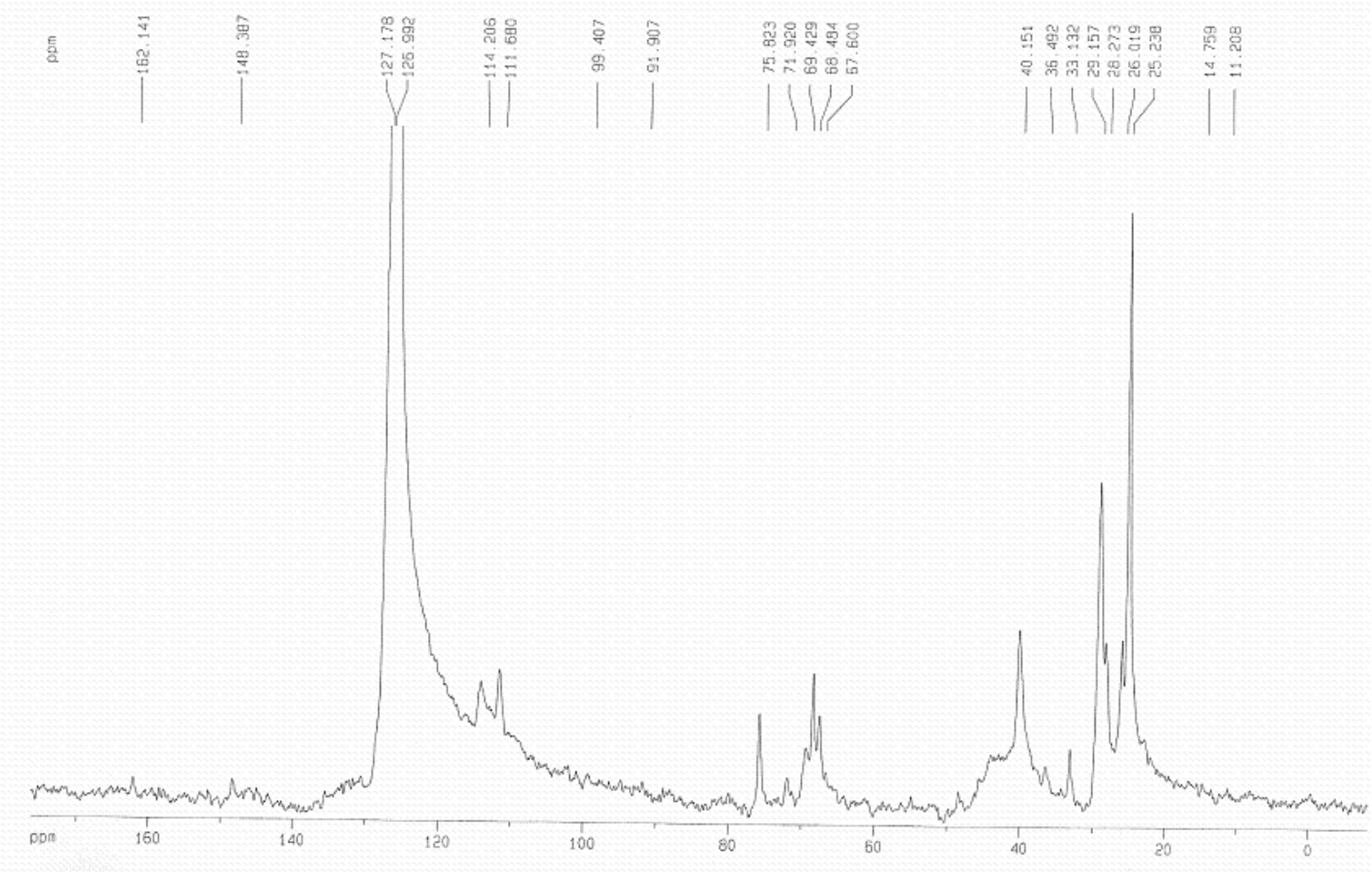

